\title{
Spatial Qualification Tests for Highly Selective Compact Micromachined Band Pass Planar Filters
}

\author{
Raghida Hajj, ${ }^{1}$ Matthieu Chatras, ${ }^{2}$ Pierre Blondy, ${ }^{2}$ Olivier Vendier, ${ }^{3}$ \\ Wolfgang Tschanum, ${ }^{4}$ and Frederic Courtade ${ }^{5}$ \\ ${ }^{1}$ CSAM IEMN UMR 8520, Université de Lille 1/CNRS, Avenue Poincaré, Cité Scientifique, 59650 Villeneuve d'Ascq, France \\ ${ }^{2}$ XLIM UMR 6172, Université de Limoges/CNRS, 123 Avenue Albert Thomas, 87060 Limoges Cedex, France \\ ${ }^{3}$ Thales Alénia Space, 26 Avenue Jean François Champollion 31100 Toulouse, France \\ ${ }^{4}$ Reinhardt Microtech AG, Aeulistraße 10, 7323 Wangs, Switzerland \\ ${ }^{5}$ CNES, 18 Rue Edouard Belin, 31000 Toulouse, France
}

Correspondence should be addressed to Raghida Hajj, raghidaelhajj@yahoo.com

Received 1 June 2012; Accepted 20 August 2012

Academic Editor: Fermín Mira

Copyright (c) 2012 Raghida Hajj et al. This is an open access article distributed under the Creative Commons Attribution License, which permits unrestricted use, distribution, and reproduction in any medium, provided the original work is properly cited.

\begin{abstract}
A highly selective planar band pass filter is proposed for satellite receivers to suppress intermodulation components. The 4-pole filter has a center frequency of $19.825 \mathrm{GHz}$ with a bandwidth of $240 \mathrm{MHz}$. The measured quality factor is over 600 and the insertion losses are $4.1 \mathrm{~dB}$. The micromachining technological process is used to fabricate this filter. A BCB (benzocyclobutene) thin layer is used as an electrical and mechanical support for the filter. The compatibility of the BCB with the spatial constraints was tested. Various tests were accomplished for this purpose and the results of all these tests are presented in the paper. The tests showed a very small influence of the temperature variation and high temperature storage test and practically no influence of the radiation test on the circuit.
\end{abstract}

\section{Introduction}

Today's world is a vast network of global communication. Technology has improved the way in which human beings communicate and transfer information. Although a number of different technical developments have contributed to this improvement, it can be argued that the technology of wireless communications has had a greater impact on modern communications than any other single technology. Wireless industry is the subject of various research works for different applications $[1,2]$. The use of satellite systems is one way to achieve wireless communication [3]. In these systems as in all wireless systems, it is very important to achieve very compact and low-cost components. To reach these goals, the choice of the technology is very important. Wireless devices have clearly benefited from the utilization of integrated circuits in many ways, most notably their size and thus portability. The objective of this work is to fabricate compact filters for suppression of intermodulation products in satellite receivers.
Planar circuits are very good candidate in terms of size and cost. But at high frequencies, they suffer from important dielectric and radiation losses. Micromachining [4-8] consists of etching a substrate to form cavities and waveguides. These formed elements could be used to design filters in volumetric $[9,10]$ or in planar topologies $[11,12]$. The micromachining process associated with cavity assembly allows the resolution of planar circuit problems and thus working at higher frequencies [12] which also means better rates of transmission of the system. In this case, the circuit is deposited on a thin dielectric BCB layer [11-13] which is newly used in spatial applications and needs to be tested for compatibility.

\section{Filter Topology, Technology, and Measurements}

The designed filter has to meet very strict specifications which are center frequency $f_{0}=19.825 \mathrm{GHz}$, bandwidth $=$ $240 \mathrm{MHz}$, and very high rejections equal to $50 \mathrm{~dB}$. To achieve 


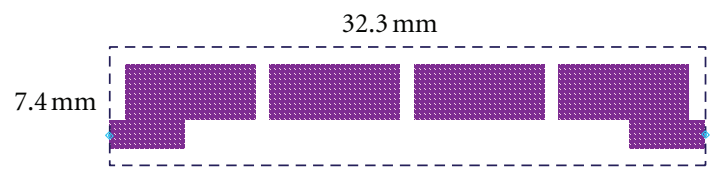

FIgURE 1: The four-pole filter topology.

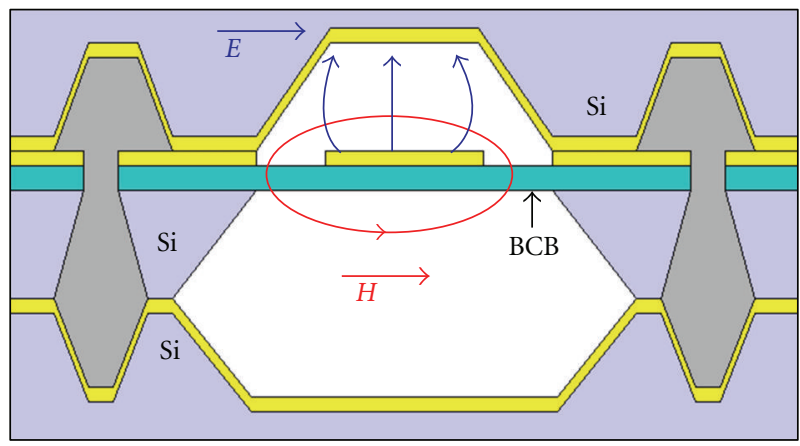

Figure 2: Cross-view of the filter.

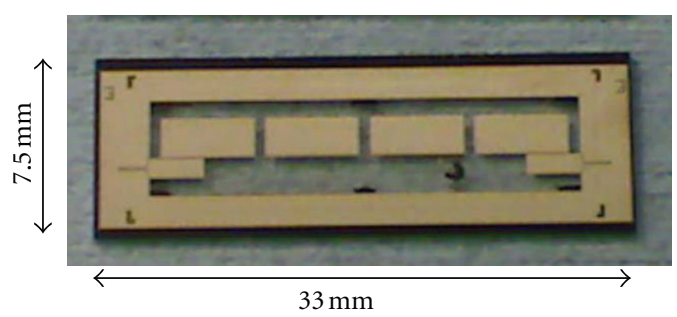

Figure 3: Top view of the membrane suspended filter.

this narrow band, a high quality factor (over 600) is needed. That is why micromachined planar filter topology is a good option. The width of the resonators and the height of the cavity have been chosen to ensure a high quality factor. Four resonators are needed to obtain a rejection of $50 \mathrm{~dB}$, close to the bandwidth. A top view and the dimensions of the proposed filter are shown in Figure 1.

The filter is composed of a high resistivity silicon substrate, a BCB thin layer $(8 \mu \mathrm{m})$ with the following characteristics $\varepsilon_{r}=2.31$ and $\operatorname{tg} \delta=10^{-3}$. The metallic resonators and feeding lines are in gold ( $3 \mu \mathrm{m}$ thick). The filter is composed of 3 silicon wafers which are micromachined using a TMAH solution. The top and bottom wafers are assembled on the central wafer to shield the structure and remove radiation losses. The upper cavity height is $425 \mu \mathrm{m}$ and the lower one is $760 \mu \mathrm{m}$. Propagation is then in air enabling high quality factor which has been measured around 600. Figure 2 shows a cut view of the filter.

Figures 3, 4, and 5 show, respectively, the filter before packaging, the shielded filter, and the CPW accesses (used for the measurements).

Figure 6 shows the comparison between simulations and measurements.

The measurements are very close to the simulations in terms of bandwidth $(240 \mathrm{MHz})$ and central frequency

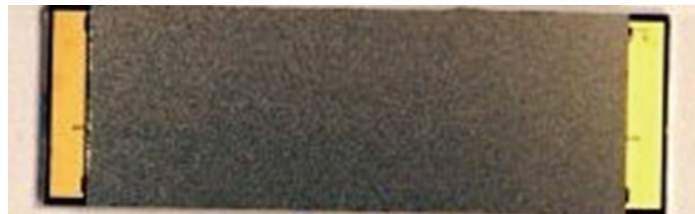

FIgURe 4: Top view of the shielded 4-pole filter.

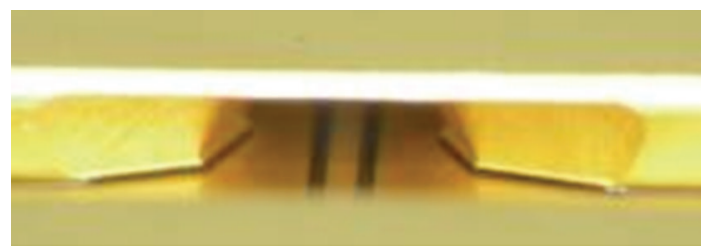

FIGURE 5: CPW access of the filter.

$(19.825 \mathrm{GHz})$. The rejection level required is also verified. The measured insertion losses $(4.1 \mathrm{~dB})$ are in coherence with the simulated losses if we add the losses due to the access lines to the simulated ones $(1 \mathrm{~dB})$.

\section{Spatial Tests}

Spatial tests are necessary to check the capability of such filters to be used in geostationary satellite systems. The different performed tests and results are described in the following subsections. The tests are based on applicable standards for integrated components in geostationary satellites.

3.1. Temperature Test. Some of the most interesting features of the filters are its thermal behavior. In Figure 7 , the measured $S$ parameters of the filter at $35^{\circ} \mathrm{C}$ and $65^{\circ} \mathrm{C}$ are compared. The difference is not very significant; a shift lower than $10 \mathrm{MHz}$ is obtained. The corresponding standard is ESA PSS-01-612/Mil STD 883-Method 1004. The test is also called moisture resistance test.

3.2. Radiation Test. The second test is a radiation test which consists of hitting the circuits with gamma rays of high energy using an accelerator. This test shows that there is no influence on the filter due to radiation as shown in Figure 8.

3.3. High Temperature Storage. The last test is a high temperature storage (HTS) test which means that the device is stored at $125^{\circ} \mathrm{C}$ during 2000 hours. The corresponding standard is ESA PSS-01-612/Mil STD 883-Method 1008, "B." The HTS test is used to determine the stability of the device in high temperature environment. 


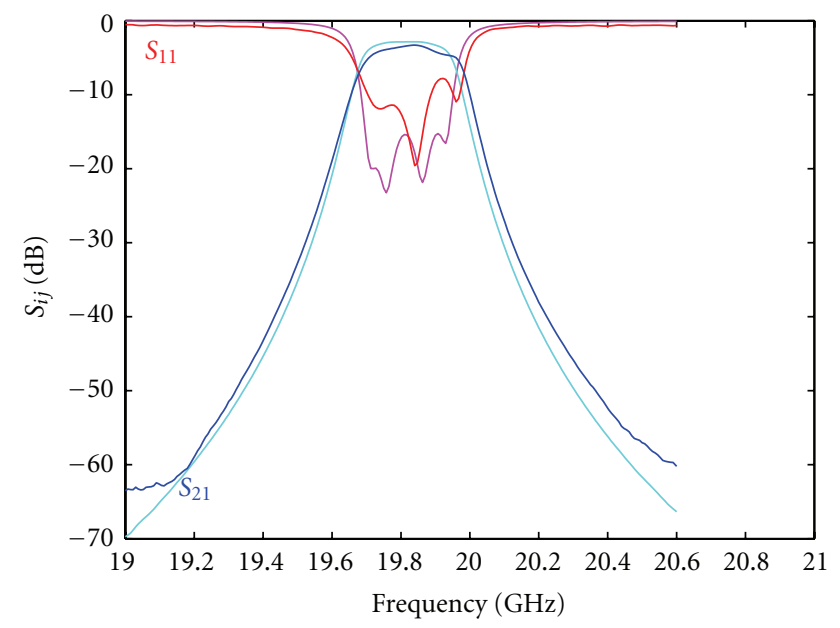

$\begin{array}{ll}\text { Measurements } & \text { Simulations } \\ \text { Measurements } & \text { Simulations }\end{array}$

FIGURE 6: Comparison of the measured and simulated $S$ parameters.

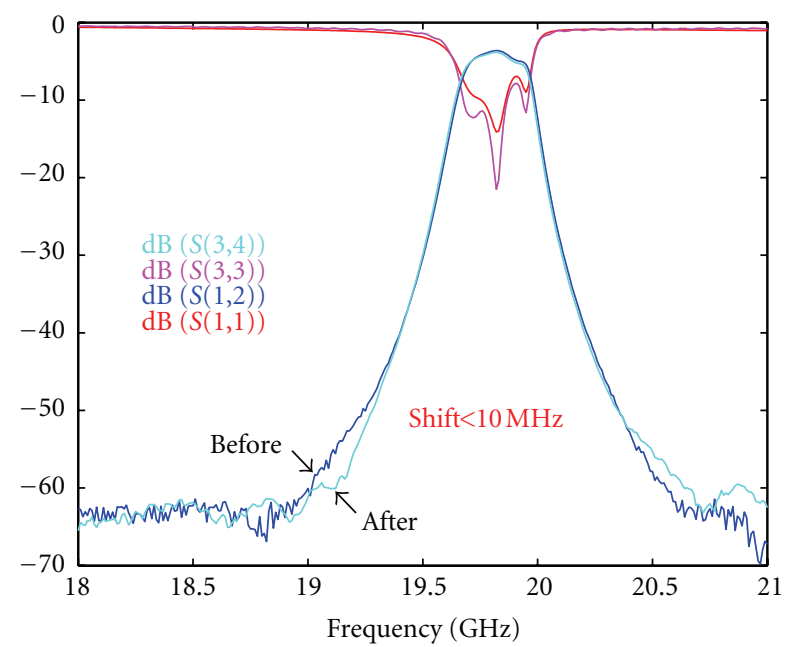

FIGURE 7: Measured influence of the temperature variation on the $S$ parameters of the filter.

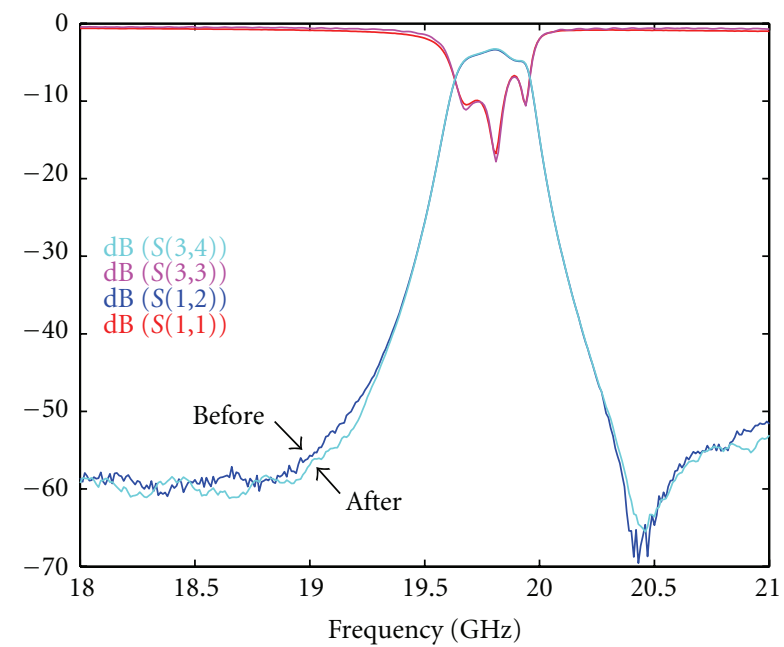

FIGURE 8: Measured influence of the radiation test on the filter.

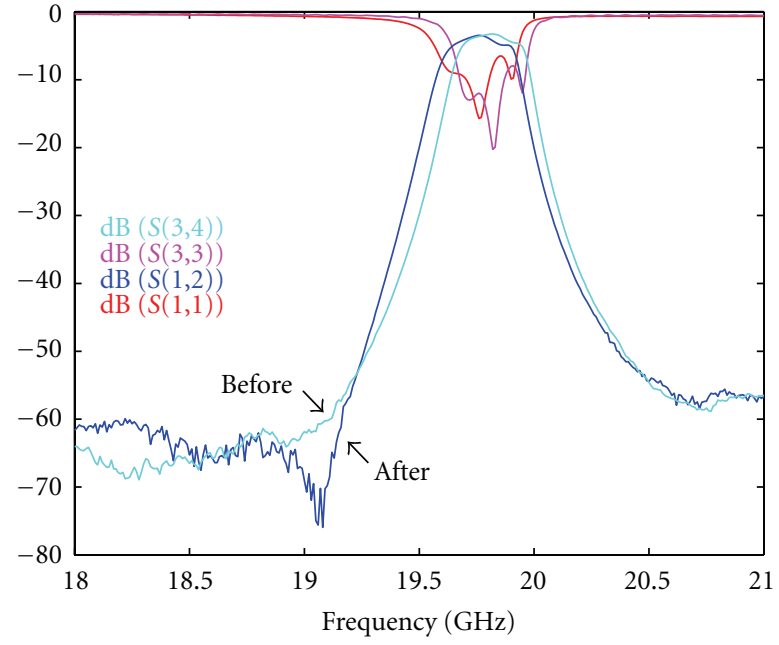

FIGURE 9: Measured influence of the high temperature storage of the filter.

This test causes a shift of $80 \mathrm{MHz}$ in the filter response as shown in Figure 9. This shift could be taken into account for new fabrications.

\section{Conclusion}

In this paper, we have presented the design of a four-pole micromachined filter. Measurements and spatial tests have been performed on this filter. Very good measurement results have highlighted the behavior of BCB micromachined band pass filter for wireless applications.

\section{References}

[1] H. Gacanin, M. Salmela, and F. Adachi, "Performance analysis of analog network coding with imperfect channel estimation in a frequency-selective fading channel," IEEE Transactions on Wireless Communications, vol. 11, no. 2, pp. 742-750, 2012.

[2] A. A. Bhorkar, M. Naghshvar, T. Javidi, and B. D. Rao, "Adaptive opportunistic routing for wireless Ad Hoc networks," IEEE/ACM Transactions on Networking, vol. 20, no. 1, pp. 243256, 2012.

[3] T. Hatsuda, K. Hashimoto, J. Masuda, and J. Murakami, "Diversity systems comparison of satellite visibility improvement for designing mobile broadcasting satellite system," IEEE Transactions on Antennas and Propagation, vol. 54, no. 8, pp. 2365-2370, 2006.

[4] A. Margomenos, Y. Lee, A. Jain, T. Yao, D. Peroulis, and L. P. B. Katehi, "Wideband micromachined transitions for MEMS tunable high-Q filters," in Proceedings of the 36th European Microwave Conference (EuMC '06), pp. 1336-1339, Ann Arbor, Mich, USA, September 2006.

[5] Y. Lee, J. P. Becker, J. R. East, and L. P. B. Katehi, "Fully micromachined finite-ground coplanar line-to-waveguide transitions for W-band applications," IEEE Transactions on Microwave Theory and Techniques, vol. 52, no. 3, pp. 10011007, 2004.

[6] J. D. Martínez, P. Blondy, A. Pothier, D. Bouyge, A. Crunteanu, and M. Chatras, "Surface and bulk micromachined RF MEMS capacitive series switch for watt-range hot switching operation," in Proceedings of the 37th European Microwave 
Conference (EUMC '07), pp. 1237-1240, Munich, Germany, October 2007.

[7] S. Lucyszyn, K. Miyaguchi, H. W. Jiang et al., "Micromachined RF-coupled cantilever inverted-microstrip millimeter-wave filters," Journal of Microelectromechanical Systems, vol. 17, no. 3, pp. 767-776, 2008.

[8] I.-J. Hyeon, W.-Y. Park, S. Lim, and C.-W. Baek, "Millimeterwave filter using novel micromachined substrate integrated waveguide structure with embedded silicon vias in BCB dielectrics," in Proceedings of the Solid-State Sensors, Actuators and Microsystems Conference, pp. 2482-2485, 2011.

[9] S. Song, C. S. Yoo, and K. S. Seo, "W-band bandpass filter using micromachined air-cavity resonator with current probes," IEEE Microwave and Wireless Components Letters, vol. 20, no. 4, pp. 205-207, 2010.

[10] X. Zhao, J. F. Bao, G. C. Shan et al., "D-band micromachined silicon rectangular waveguide filter," IEEE Microwave and Wireless Components Letters, vol. 22, no. 5, 2012.

[11] M. Chatras, P. Blondy, D. Cros, O. Vendier, and J. L. Cazaux, "A surface-mountable membrane supported filter," IEEE Microwave and Wireless Components Letters, vol. 13, no. 12, pp. 535-537, 2003.

[12] R. Hajj, M. Chatras, P. Blondy, L. Rigaudeau, and J. Puech, "Two-pole micromachined bandpass filter at $150 \mathrm{GHz}$ with $4 \% 3 \mathrm{~dB}$ bandwidth," Electronics Letters, vol. 46, no. 12, pp. 843-845, 2010.

[13] P. Ferrand, M. Chatras, D. Baillargeat et al., "Compact quasi planar silicon bandpass filters based on metallic periodic structure for Q and V band applications," in Proceedings of the IEEE MITT-S International Microwave Symposium Digest, pp. 1459-1462, June 2004. 

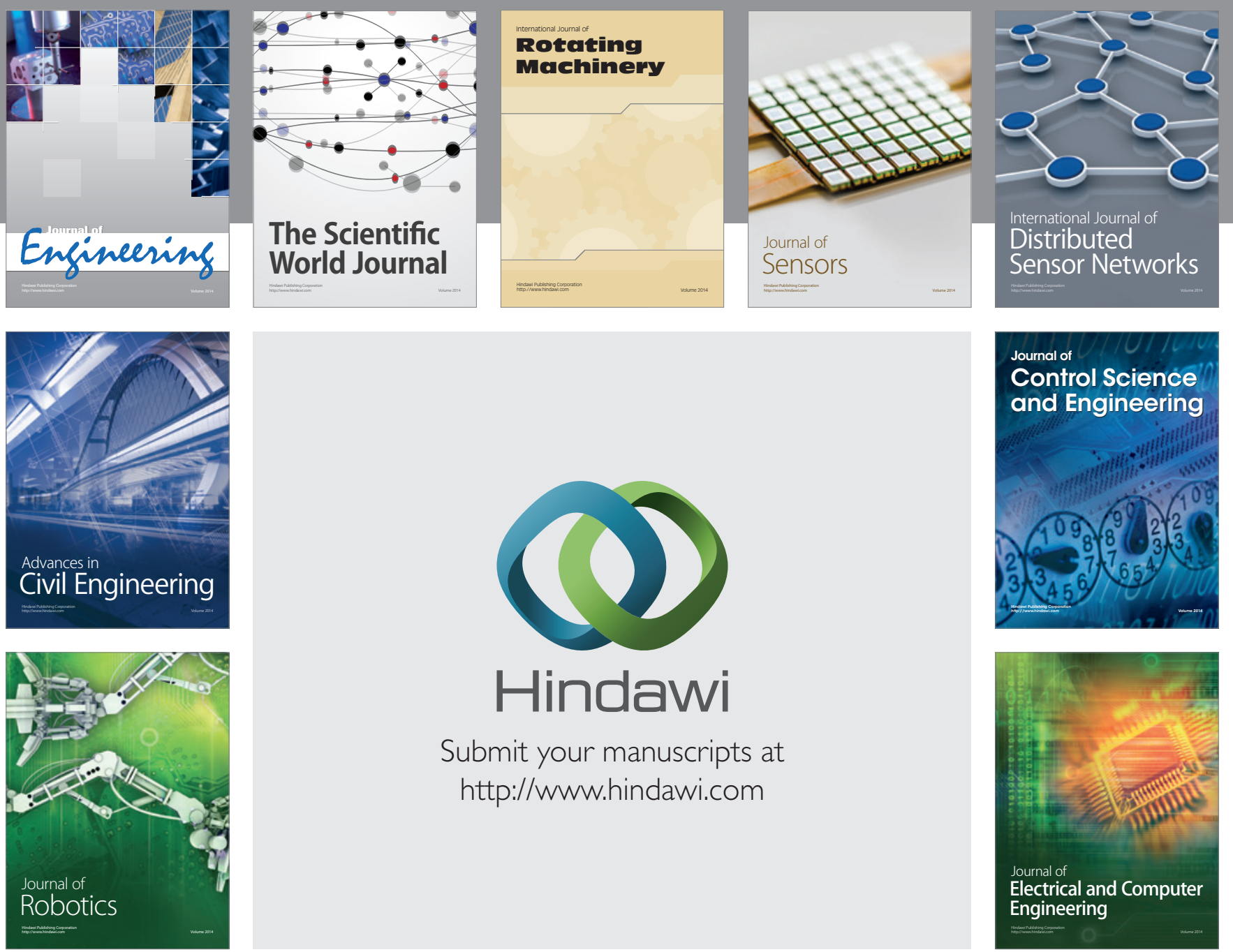

Submit your manuscripts at

http://www.hindawi.com
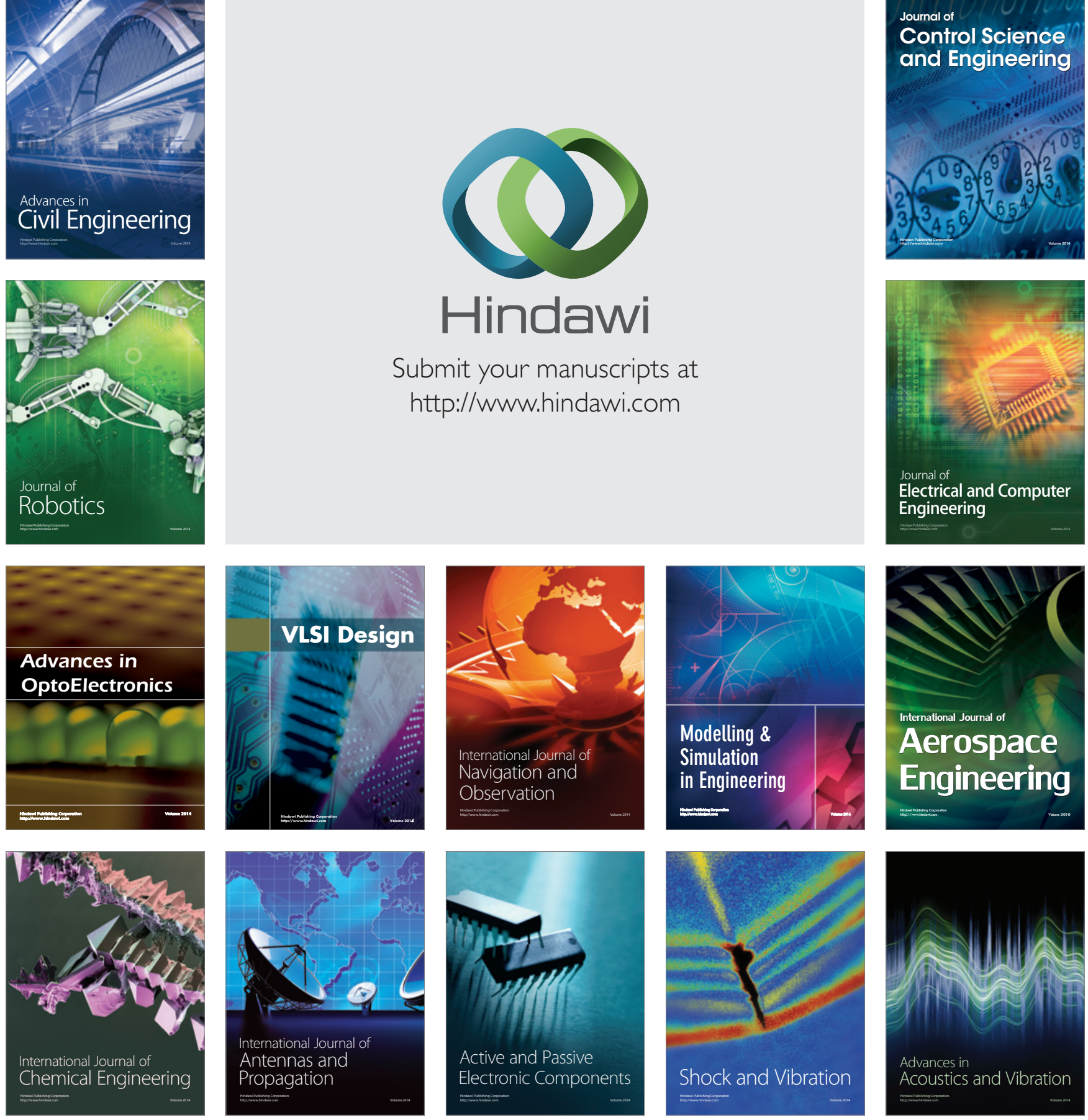